\title{
Recognizing Culturally Related Findings on Refugee Physical Examinations
}

\author{
Ellen Einterz, MD, MPHETM
}

On physical examination, refugees from countries in Africa, Asia, and the Middle East often present with findings that are unfamiliar to primary health care providers in the West. Previous traditional practices that may have left their mark include scarification and burning of the skin, excision of body parts, and subcutaneous insertion of foreign material. The descriptions detailed here introduce providers to some of the signs that result from body modification practices commonly encountered on physical examination of refugees. (J Am Board Fam Med 2018;31:653-657.)

Keywords: Africa, Asia, Health Personnel, Middle East, Physical Examination, Refugees

Although few North American health care providers are surprised when they see patients with pierced earlobes, capped teeth, snipped foreskins, or shaved axillary hair, some may be surprised or confused to see clients with amputated uvulas or beads embedded under the skin of their genitalia. Culture sometimes dictates that individuals alter the integrity of their bodies for reasons considered salutary, attractive, religiously mandated, or ritualistically important. With the world in the midst of one of the largest and most widespread refugee crises ever known ${ }^{1}$, primary care providers should benefit from being familiar with the more common forms of body modification encountered on physical examination of patients from refugee countries.

This article was externally peer reviewed.

Submitted 18 September 2017; revised 6 December 2017; accepted 10 December 2017.

From Marion County Public Health Department, and Indiana University School of Medicine and Fairbanks School of Public Health Indianapolis, Indiana.

Funding: none.

Conflict of interest: none declared.

Corresponding author: Ellen Einterz, MD, MPH\&TM, Marion County Public Health Department, and Indiana University School of Medicine and Fairbanks School of Public Health Indianapolis, 6160 N. Ewing Street, Indianapolis, IN 46220 (E-mail: emeinterz@yahoo.com).

Ethical approval: Because there was no medical record review or pulling of data from records, IRB review and approval was not required, and a statement from the IRB was given to this effect. The figures were approved by the Marion County Public Health Department Privacy Officer.
Four categories provide one way of grouping these modifications: scarification, burning, excision, and insertion.

\section{Scarification}

Scarification, from the Greek skariphos, meaning sketch $^{2}$, is the process of using razor blades or specially fashioned instruments to make superficial incisions in the skin.

Decorative or ritualistic scarification (Figure 1), which entails groupings of parallel lines incised in a symmetrical pattern over some part of the body, is meant to enhance beauty, to signal that a person belongs to a particular social group, or that he or she has successfully completed a rite of passage. Practitioners might rub ash or vegetable matter into the wounds to render the eventual scars more pronounced. ${ }^{3,4}$ Traditional healers also scarify for the purpose of countering pain, reducing swelling, or slowing a racing heart. They may knead herbal medicines into the nicks to enhance an intended therapeutic effect. $^{4-6}$

Preadolescent and adolescent boys from refugee camps in East Africa sometimes sport self-inflicted single vertical welts approximately $5 \mathrm{~mm} \times 15 \mathrm{~mm}$ over their left distal biceps. To obtain a mark that resembles that of his comrades, a boy pinches the soft inside of his upper arm, progressively removing layers of skin until the wound created is deep enough to produce a permanent scar. In contrast to the adolescents' self-inflicted defacements, scars made by some African traditional healers to treat 
Figure 1. Decorative scarification of a child's face.

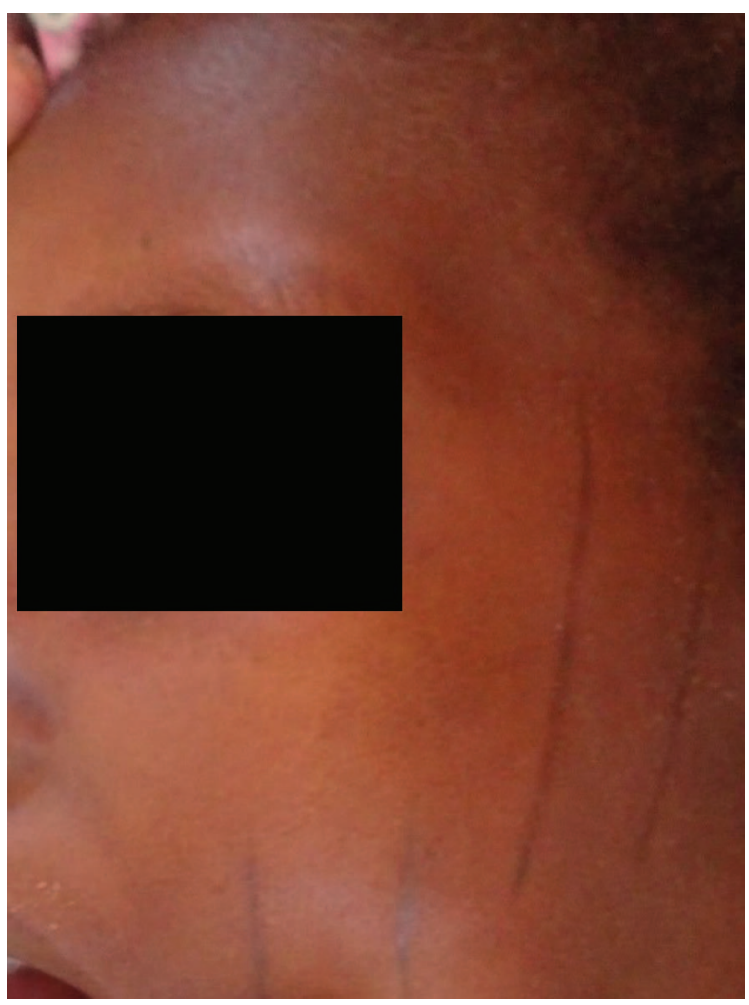

jaundice are typically horizontal and bilateral (Figures 2,3) rather than vertical and unilateral.

The scar left by the Bacillus Calmetter-Guérin (BCG) vaccination is another sign seldom found on Westerners but usually found on refugees, most of whom come from countries where BCG vaccination is routinely administered at birth. This is a 6-mm to 7-mm roundish, slightly shiny mark located on the

Figure 2. Distal upper arm scarification from treatment for jaundice.

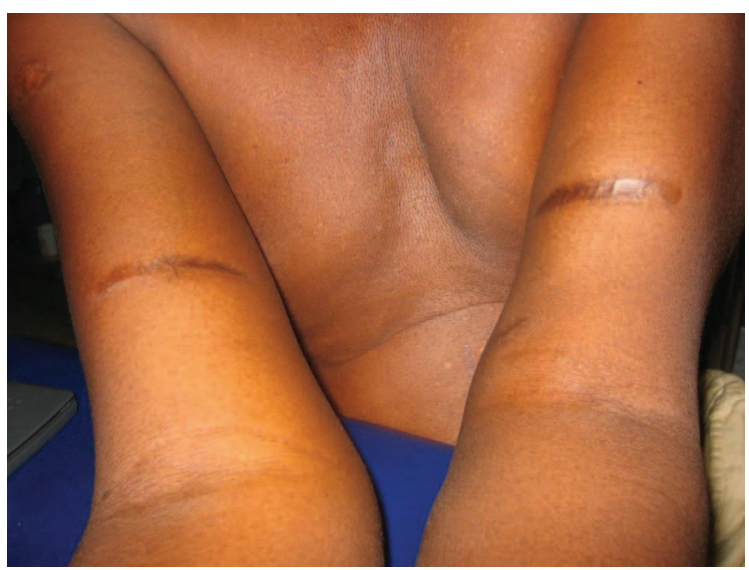

Figure 3. Distal upper arm scarification from treatment for jaundice.

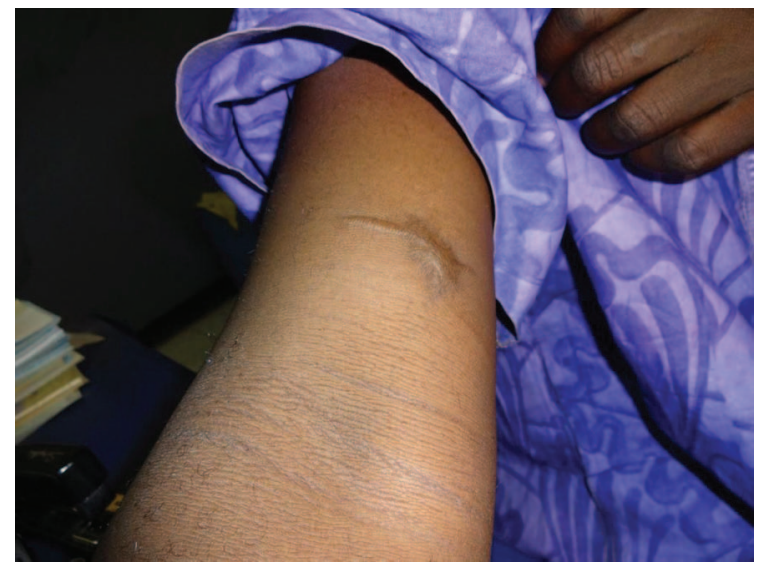

outside of the left (but occasionally right) upper arm or on the anterior (but occasionally posterior) aspect of the left forearm. One can distinguish a BCG scar from other scars by its shape, position, size, and slight bulge in the center of the depression. ${ }^{7}$

\section{Burning}

Traditional healers might apply scorching heat directly to an area of a patient's body to cure an illness, or they might perform hot cupping, whereby the inside of a container such as a jar, a flask or an animal horn is heated with a burning candle or swab. The open end of the vessel is applied to the patient's skin, and as the vessel cools, a vacuum is formed. This negative pressure is believed to have the power to aspirate or extract illness. When heat is applied directly to the skin, the scar produced is ragged and irregular (Figure 4), whereas cupping (Figure 5) creates a circular and well-defined mark.

Figure 4. The posterior thorax of a Somali refugee, with scars resulting from burns intended to cure flu.

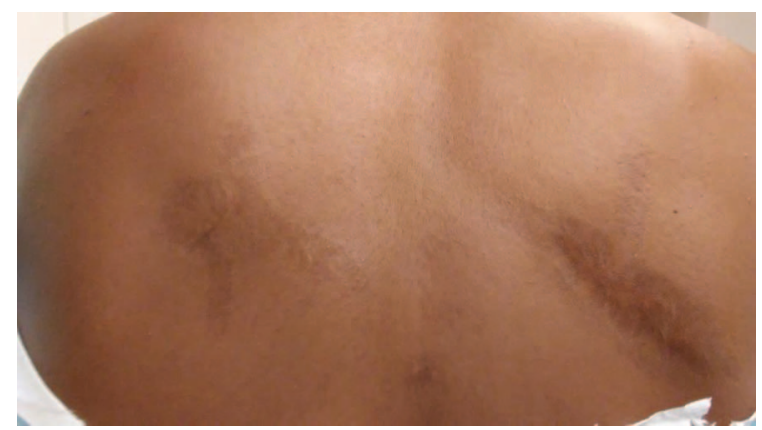


Figure 5. Scarification and burning of the anterior thorax of a Central African adolescent, inflicted as a healing measure.

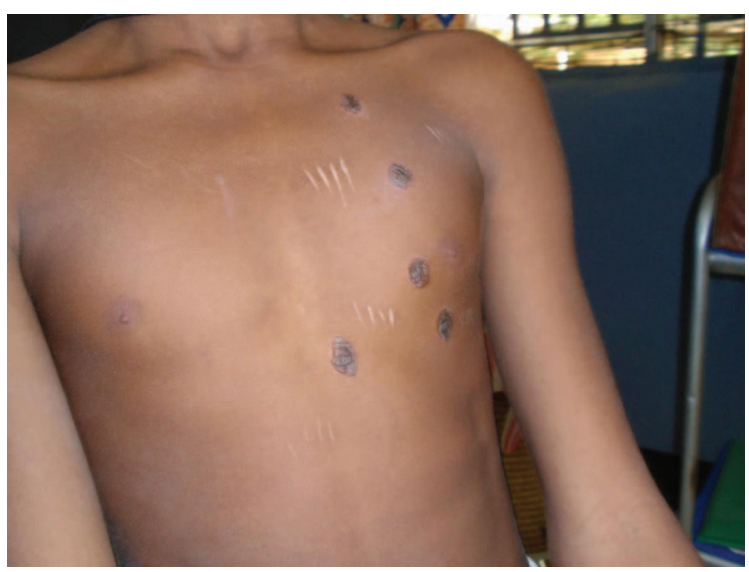

\section{Excision}

Like many procedures still performed today by traditional practitioners in different parts of the world, excision of all or part of the uvula is a centuries-old practice. It has been described recently from all corners of Africa as well as from much of the Middle East. ${ }^{8-11}$ A barber or traditional healer generally performs the operation with rudimentary instruments and without sterile technique. Although found especially in regions with a high preponderance of Muslims, theological concerns do not underpin uvulectomy. Rather, populations espouse uvuletomy as a preventive or therapeutic weapon to fight sore throat, vomiting, poor feeding, or cough. ${ }^{8,9}$ In some places, researchers have been able to identify no reason for the practice and its persistence beyond the perpetuity of cultural habit. Uvulectomy is often done during a child's first weeks of life, but adults also submit to the surgery, and some individuals whose uvulas are not entirely removed at the first operation may undergo the procedure more than once. ${ }^{10} \mathrm{Al}$ though complications following uvulectomy are unusual, hemorrhage and infection are the most common immediate problems. ${ }^{9}$ Examination of the throat of a patient who has undergone total uvulectomy reveals a smooth inverted U-shaped posterior soft palate (Figure 6). Uvulectomy does not seem to result in any recognizable impediment to speech, swallowing, or susceptibility to disease; nor has it been shown to confer any advantage.

Societies in many parts of the world continue to practice female genital mutilation and cutting
Figure 6. Adult from Ethiopia whose uvula was excised during childhood.

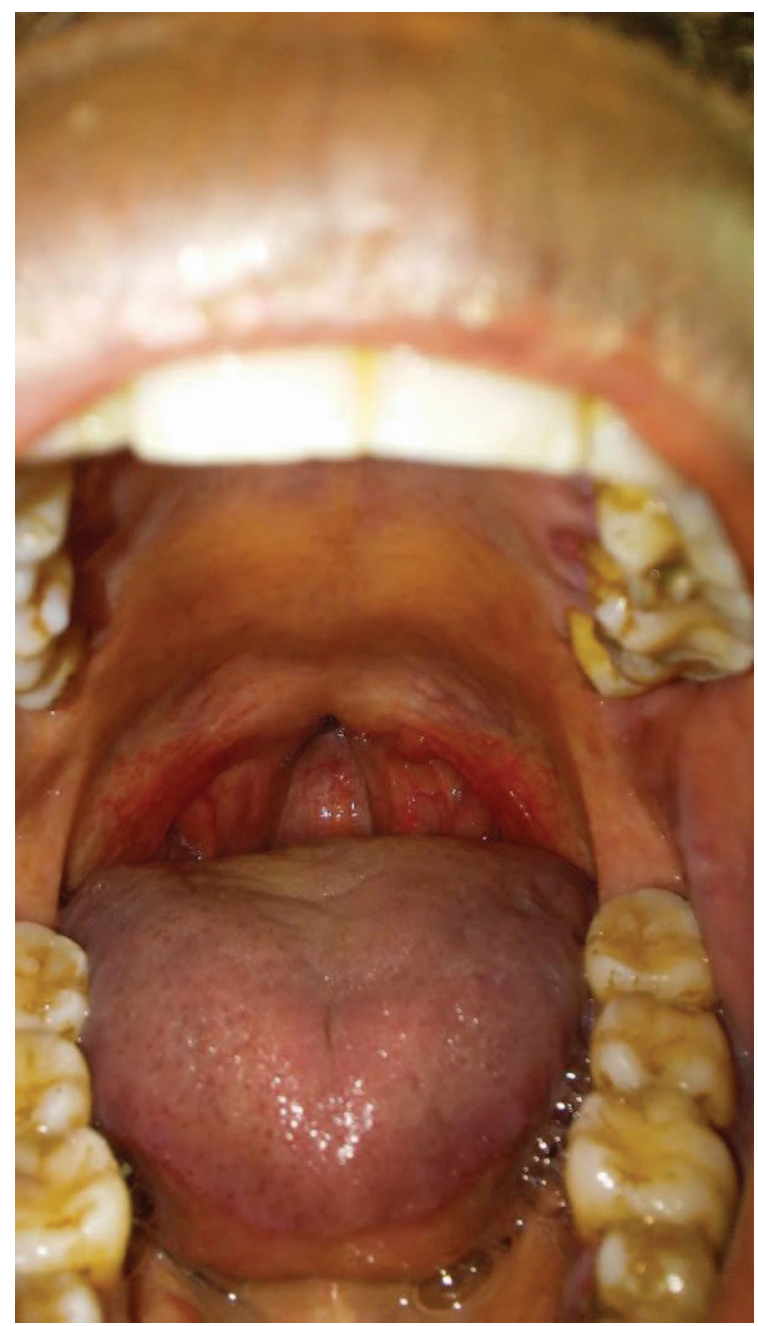

(FGM/C) for reasons ranging from tradition to suppression of feminine libido, and the practice has been extensively described and illustrated. ${ }^{12}$ Type III is the most extreme form of FGM/C and remains highly prevalent in Ethiopia, Eritrea, Somalia, and Sudan. ${ }^{13}$ This procedure involves excision of parts of the external genitalia followed by tissue closure that severely narrows or wholly seals the introitus. In a patient who has undergone extreme FGM/C, the examining physician encounters a flattened vulva devoid of clitoris and labia.

\section{Insertion}

The surgical insertion of beads under the skin of the penis, called "pearling" in colloquial English and "insertion of artificial penile nodules" in the medical literature, is another body modification 
that has been practiced for hundreds of years, most pervasively in China and Southeast Asia. The intended purpose of the practice, according to numerous reports, is to enhance partners' enjoyment of sexual intercourse, although evidence that this is achieved is lacking. ${ }^{14-17}$

The procedure involves making an incision in the skin of the penis and then creating a tunnel through which a small, smooth, hard object is pushed. The wound is either sutured closed or allowed to heal by secondary intention, securing the object inside. A penis may harbor one or several of these pellets, which are generally beads, stones, or ball bearings. When no other material is available—as, for example, when in prison-a man may resort to using pieces of plastic or glass that have been hand-ground to spherical, rectangular, or cylindrical shapes and then polished by sucking to a smooth finish. ${ }^{18}$ An unaccustomed examining eye might mistake these foreign bodies for granulomas, cysts, or phleboliths.

The fashion of inserting dye into the skin to create a tattoo is widespread throughout the world, but there are particularities about tattoos in people from many refugee countries that set them apart. In Myanmar, where tattoos have had a long history of being alternately encouraged by society and banned by the government, inked pictorial or literal messages have expressed solidarity with insurgents, romantic love, religious devotion, and mystical protection. ${ }^{19}$ Elaborate facial tattoos, still seen occasionally on older Burmese women, were a sign of ethnic identity and readiness for marriage. Expertly drawn, intricate works of art often decorate the torso, neck, or limbs of adults, while do-it-yourself inscriptions and crudely drawn simple designs are also common, especially among the young.

\section{Implications}

Gaining a better understanding of the body modification practices cited here should temper suspicions of torture, child abuse, or mental illness when a medical provider encounters for the first time a refugee who has been subject to one of these practices. In some cases, it can help with diagnosis and discovery of past medical history, suggesting avenues for the clinician to explore: marks over the left upper quadrant might indicate a past finding of splenomegaly from repeated episodes of malaria,
Figure 7. Scarification of a child from West Africa, performed in an attempt to treat tachycardia due to anemia.

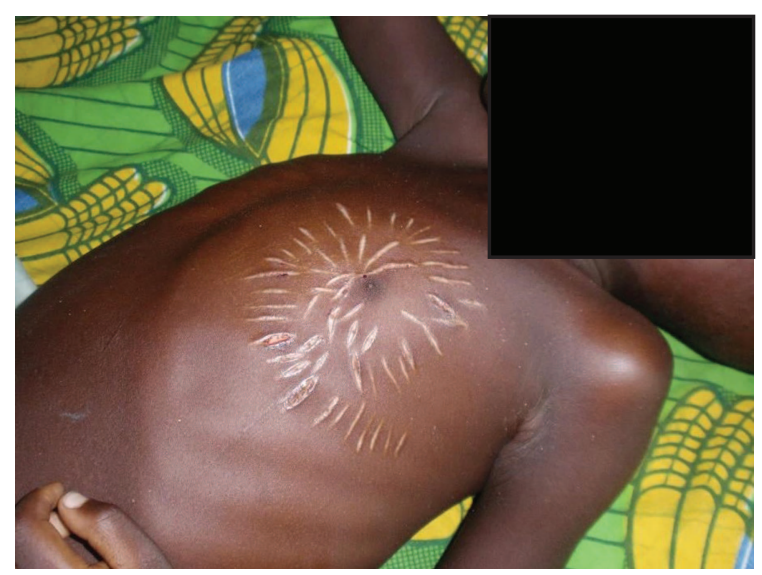

for example; cuts over the precordium might point to a history of severe anemia (Figure 7); right upper-quadrant scars might signal old hepatitis; and incisions over the epigastrium might denote past gastritis or peptic ulcer. Finding that a woman has undergone FGM/C gives the clinician an opportunity to explain to her that in her new country, FGM/C is illegal and that attempting to have her daughter cut would be considered a criminal offense. Because any unsterile operative procedure can be a pathway for the transmission of pathogens, evidence of such intervention should be an indication to screen for hepatitis and HIV. Finally, while adding to their effectiveness as communicators and healers, health workers' greater cultural awareness is correlated with greater satisfaction not only for them but also for the refugee patients in their care. $^{20,21}$

The author thanks Katrina Thielman for preparation of the photographs and the entire Marion County Public Health Department refugee health care team for their daily support and dedication.

To see this article online, please go to: bttp://jabfm.org/content/ 31/4/653. full.

\section{References}

1. United Nations High Commissioner for Refugees. UNHCR Statistics: the world in numbers. Available from: http://popstats.unhcr.org/en/overview\#_ga = 2.154846840.1365918570.1512420071-2145398117. 1510342168. Published 2017. 
2. Kazhdan AP. Oxford Dictionary of Byzantium. Location: New York, NY: Oxford University Press; 1991.

3. Schildkrout E. Inscribing the body. Annu Rev Anthropol 2004;33:319-44.

4. Garve R, Garve M, Türp JC, Fobil JN, Meyer CG. Scarification in sub-Saharan Africa : social skin, remedy and medical import. Trop Med Int Health 2017; 22:708-15.

5. Richard SA, Mathieu E, Addiss DG, Sodahlon YK. A survey of treatment practices and burden of lymphoedema in Togo. Trans R Soc Trop Med Hyg 2007;101:391-7.

6. Dambisya YM, Tindimwebwa G. Traditional remedies in children around Eastern Cape, South Africa. East Afr Med J 2003;80:402-405.

7. Hershfield E, Roche B. Recognition of BCG scars. University of Manitoba Tuberculosis Research Unit 2004. Available from: www.phac-aspc.gc.ca/tbpclatb/pdf/recognition-bcg-scars_e.ppt.

8. Adoga AA, Nimkur TL. The traditionally amputated uvula amongst Nigerians: still an ongoing practice. Otolaryngology 2011;2011:704924.

9. Einterz EM, Einterz RM, Bates ME. Traditional uvulectomy in northern Cameroon. Lancet 1994; 343:1644.

10. Adebola SO, Ogunkeyede SA, Obebe FA, Olaniyan OD, Fawole OB, Salman A. Profile of pediatric traditional uvulectomy in North-West Nigeria: the need for caution and education. Int J Pediatr Otorhinolaryngol 2016;88:194-8.
11. Rubinstein A. Absence of uvula in South Sinai Bedouins. JAMA 1979;242:323.

12. Abdulcadir J, Catania L, Hindin MJ, Say L, Petignat P, Abdulcadir O. Female genital mutilation: a visual reference and learning tool for health care professionals. Obstet Gynecol 2016;128:958-963.

13. UNICEF report on Female Genital Mutilation/Cutting, 2013. Available from: https://www.unicef.org/ protection/files/00-FMGC_infographiclow-res.pdf.

14. Gilmore WA, Weigand MD, Burgdorf WHC. Penile nodules in Southeast Asian men. Arch Dermatol 1983;119:446-7.

15. Sugathan PP. Bulleetus. Int J Dermatol 1987;26:51.

16. Norton SA. Fijian penis marbles: an example of artificial penile nodules. Cutis 1993;51:295-297.

17. Wilcher G. Artificial penile nodules-a forensic pathosociology perspective: four case reports. Med Sci Law 2006;46:349-56.

18. Lim KB, Seow CS, Tulip T, Daniel M, Vijayasingham SM. Artificial penile nodules: case reports. Genitourin Med 1986;62:123-5.

19. Paquette D. Tattoo not taboo. The Irrawaddy 2008; 16(2). Available from: http://www2.irrawaddy.com/ article.php? art_id=10096\&page $=1$.

20. Cobb TG. Strategies for providing cultural competent health care for Hmong Americans. J Cult Divers 2010;17:79-83.

21. Alpern JD. Perceived barriers to success for resident physicians interested in immigrant and refugee health. BMC Med Educ 2016;6:178. 